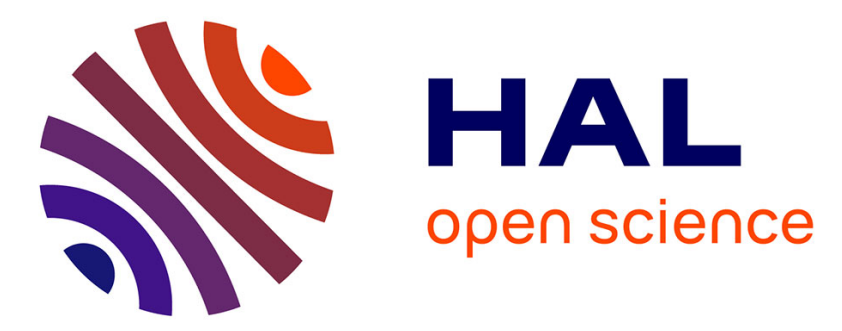

\title{
Phase behaviour of thermoplastic interpenetrating polymer networks by thermal and mechanical measurements
}

\author{
A. Bartolotta, Giuseppe Carini, Giovanna d'Angelo, G. Di Marco, Sergio La \\ Rocca, O.P. Grigoryeva, Ludmila Sergeeva, Olga Slisenko, O. Starostenko, \\ Gaspare Tripodo
}

\section{To cite this version:}

A. Bartolotta, Giuseppe Carini, Giovanna d'Angelo, G. Di Marco, Sergio La Rocca, et al.. Phase behaviour of thermoplastic interpenetrating polymer networks by thermal and mechanical measurements. Philosophical Magazine, 2007, 87 (3-5), pp.723-730. 10.1080/14786430600920821 . hal-00513754

\author{
HAL Id: hal-00513754 \\ https://hal.science/hal-00513754
}

Submitted on 1 Sep 2010

HAL is a multi-disciplinary open access archive for the deposit and dissemination of scientific research documents, whether they are published or not. The documents may come from teaching and research institutions in France or abroad, or from public or private research centers.
L'archive ouverte pluridisciplinaire HAL, est destinée au dépôt et à la diffusion de documents scientifiques de niveau recherche, publiés ou non, émanant des établissements d'enseignement et de recherche français ou étrangers, des laboratoires publics ou privés. 


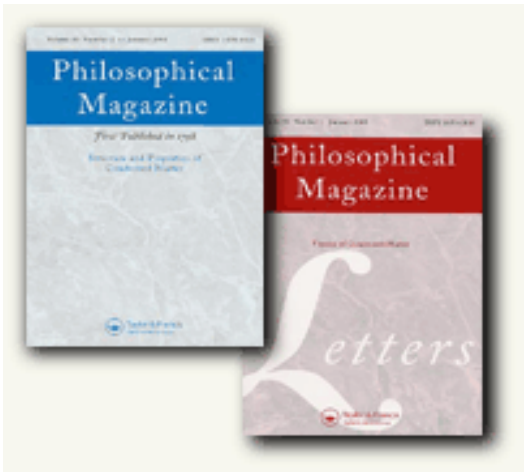

\section{Phase behaviour of thermoplastic interpenetrating polymer networks by thermal and mechanical measurements}

\begin{tabular}{|r|l|}
\hline Journal: & Philosophical Magazine \& Philosophical Magazine Letters \\
\hline Manuscript ID: & TPHM-06-Apr-0125.R1 \\
\hline Journal Selection: & Philosophical Magazine \\
\hline Author: & 12-Jul-2006 \\
\hline & $\begin{array}{l}\text { Bartolotta, A.; Istituto per i Processi Chimico-Fisici, CNR } \\
\text { carini, giuseppe; University of Messina, Dept of Physics } \\
\text { D'Angelo, Giovanna; university of messina, physics } \\
\text { Di Marco, G.; Istituto per i Processi Chimico-Fisici, CNR } \\
\text { La Rocca, Sergio; university of messina, physics } \\
\text { Grigoryeva, O.P.; National Academy of Sciences of Ukraine, } \\
\text { Institute of Macromolecular Chemistry } \\
\text { Sergeeva, Ludmila; National Academy of Sciences of Ukraine, } \\
\text { Institute of Macromolecular Chemistry } \\
\text { Slisenko, Olga; National Academy of Sciences of Ukraine, Institute } \\
\text { of Macromolecular Chemistry } \\
\text { Starostenko, O.; National Academy of Sciences of Ukraine, Institute } \\
\text { of Macromolecular Chemistry } \\
\text { Tripodo, Gaspare; university of messina, physics }\end{array}$ \\
\hline Keywords: & $\begin{array}{l}\text { amorphous solids, mechanical properties, polymers, thermal } \\
\text { properties }\end{array}$ \\
\hline Keywords (user supplied): & \begin{tabular}{l} 
\\
\hline
\end{tabular} \\
\hline
\end{tabular}

\section{(5) ScholarONE" \\ Manuscript Central}




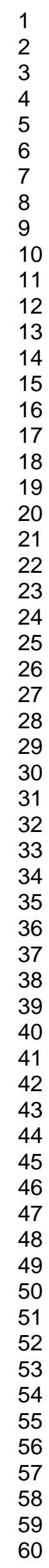

http://mc.manuscriptcentral.com/pm-pml 


\title{
Phase behaviour of thermoplastic interpenetrating polymer networks by thermal and mechanical measurements
}

\author{
A. Bartolotta ${ }^{1}$, G. Carini ${ }^{2}$, G. D'Angelo ${ }^{2}$, G. Di Marco ${ }^{1}$, S. La Rocca ${ }^{2}$, O. P. Grigoryeva ${ }^{3}$, L. \\ Sergeeva $^{3}$, O. Slisenko ${ }^{3}$, O. Starostenko ${ }^{3}$, G. Tripodo ${ }^{2}$ \\ ${ }^{\text {(1) }}$ C. N. R., Istituto per i Processi Chimico-Fisici, sez. di Messina. Via La Farina, 237- 98123 \\ Messina, Italy. \\ (2) Dipartimento di Fisica and INFM, Universita' di Messina, Salita Sperone 31, I-98166, S. Agata \\ (ME), Italy.

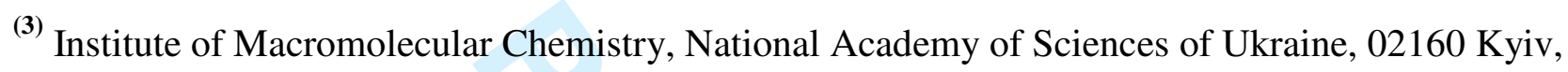 \\ Ukraine
}

\begin{abstract}
The phase behaviour of thermoplastic interpenetrating polymer networks based on semi-crystalline polyurethane and a styrene/acrylic acid block-copolymer has been investigated by experiments of differential scanning calorimetry and dynamic mechanical spectroscopy. Distinct calorimetric and mechanical transitions point to an inherent heterogeneity characterizing the structure of thermoplastic networks, mainly due to a weak affinity of the two components. At variance with these observations, deviations from a simple additive law are revealed from the composition behaviour of the melting endotherms associated to polyurethane component and of the $\gamma$ - and $\alpha_{a}{ }^{-}$ relaxation strengths. The quantitative analysis of the low temperature $\gamma$-relaxation indicates that the fraction of amorphous chains of polyurethane is enhanced on blending, this result being in close agreement with calorimetric results. All these findings suggest the formation of a mixed amorphous microphase as a consequence of specific weak interactions (H-bonds) between the functional groups of the two components.
\end{abstract}

PACS INDEX: $61.40 \mathrm{~km}$ or $62.40+\mathrm{i}$ 


\section{§ 1. INTRODUCTION}

Thermoplastic interpenetrating polymer networks ( $t$-IPNs) are multicomponent polymeric systems and can be considered as hybrid materials between linear polymer blends and classical IPNs whose structure is constructed by physical crosslinks rather than chemical cross-links [1,2]. Their components (semicrystalline polymers, block copolymer and polymer with ionic groups) are characterized by mutual penetration giving rise to a complex morphology: regions mainly built on by segments of one component are matched to regions based on the second component, substantial network interpenetration occurring at the interface. As a consequence, the mechanical properties and the molecular mobility of the whole network is strongly influenced by the domain and interface sizes. Thus $t$-IPNs are cross-linked and behave like IPNs at relatively low temperatures, while at elevated temperatures they show viscoelastic behaviour similar to that of thermoplastics. From this point of view the analysis of the relaxation dynamics represents an appropriate and unequivocal tool to study the coupling mechanism of the polymeric components and to evaluate their thermodynamic compatibility as opposite to some kind of microscopic or nanoscopic inhomogeneity.

Now $t$-IPNs obtained by the introduction of a second reactive polymer, such as block copolymers and/or polymers with ionic groups, to polyurethane (PU) permit to improve its mechanical characteristics which are inappropriate for technological applications as a consequence of the low rigidity and the high thermal expansion coefficient of PU [3]. A recent study [4] concerning the thermal and mechanical properties of one $t$-IPN sample, a blend of $80 \mathrm{wt} \%$ of semicrystalline polyurethane (cPU) and $20 \mathrm{wt} \%$ of poly(styrene- $b$-potassium acrylate) block copolymer (S-b-AK), gave indications about significant deviations of the measured properties from a simple dilution effect, leading to assume the existence of a weak miscibility of the two polymeric components.

In the present work, the structure-property relationships of $t$-IPNs based on blends of cPU and S-bAK have been more widely investigated by extending the interval of compositions examined. The totality of observations, obtained by differential scanning calorimetry (DSC) and dynamic mechanical thermal analysis (DMTA), show and confirm the existence of deviations from a simple additive law which have been associated to a weak, even if limited, compatibility of the individual components.

\section{§ 2. EXPERIMENTAL DETAILS}

The crystallisable polyurethane (cPU), the poly(styrene- $b$-acrylic acid) copolymer (S- $b$-AA, acid form) and the poly(styrene- $b$-potassium acrylate) ionomer (S- $b$-AK, salt form) were prepared following the same specific procedure elsewhere described [4,5]. Films of thermoplastic 
composites, having compositions $\frac{c P U(w t \%)}{S-b-A K(w t \%)}=\frac{90}{10}, \frac{10}{90}$ and $\frac{5}{95}$ and referred to as $t$-IPNs $[1,6,7]$, were prepared at several compositions by casting from $20 \%$-solutions in dioxane onto Teflon plates and subsequent evacuation to constant weight. In order to avoid undesirable effects due to contamination from absorbed water moisture [4], the samples were dried at about $330 \mathrm{~K}$ under vacuum of $10^{-4}$ mbar for $\sim 12 \mathrm{~h}$ before each run of measurements and then analysed by maintaining the experimental chamber under a controlled atmosphere of nitrogen. Thermograms were determined by using a Perkin-Elmer Pyris1 differential scanning calorimeter (DSC), calibrated with indium and zinc standards. All DSC curves, obtained at a heating rate of $40 \mathrm{Kmin}^{-1}$, are baseline subtracted and normalized to $1 \mathrm{mg}$ of sample.

Dynamic mechanical thermal properties (storage modulus E' and loss modulus E”) were investigated in the $120 \div 450 \mathrm{~K}$ temperature and $0.3-30 \mathrm{~Hz}$ frequency range at heating rate of $2 \mathrm{~K} / \mathrm{min}$, using a dynamic mechanical thermal analyzer (DMTA) from Polymer Laboratories.

\section{§ 3. RESULTS}

\subsection{Thermal transitions}

DSC traces of $t$-IPNs containing 90, 10 and $5 \mathrm{wt} \%$ of $\mathrm{cPU}$ (cPU/S-b-AK=90/10, 10/90 and 5/95) are compared in figure 1 to those of pure semi-crystalline cPU, pure amorphous S-b-AK and cPU/S-b-AK=80/20, already reported and discussed [4]. The 90/10 $t$-IPN exhibits a small jump at $T_{g} \cong 233 \pm 2 \mathrm{~K}$ corresponding to the glass transition of the amorphous regions and a further jump at about $300 \mathrm{~K}$, which overlaps to the distinct endothermic peak at $T_{m}=330 \mathrm{~K}$ (heat of melting $\Delta H_{m} *$ $=50 \pm 3 \mathrm{~J} \mathrm{~g}^{-1}$ ) associated to the melting of oligomeric butylene adipate glycol (BAG) microcrystals of cPU [4]. $t$-IPNs having weight fractions of 10/90 and 5/95 show sudden, well defined jumps at $T_{g}$ $\cong 343 \pm 2 \mathrm{~K}$ and $T_{g} \cong 357 \pm 2 \mathrm{~K}$, corresponding to the glass transition of the S-b-AK component.

\subsection{Mechanical transitions}

The experimental results for the loss modulus E"(T) at $3 \mathrm{~Hz}$ for the 90/10 sample are compared to those previously reported [4] of pure cPU and cPU/S-b-AK=80/20 in figure $2 a$, while those for the samples with low cPU contents (10/90 and 5/95) are compared to the one of pure S-b-AK [4] in figure $2 \mathrm{~b}$. As the temperature is increased from $120 \mathrm{~K}$ to $200 \mathrm{~K}, \mathrm{E}$ "(T) of 90/10 sample (figure 2a) increases and passes through the $\gamma$-relaxation peak, located at about the same temperature $(158 \mathrm{~K}$ at $3 \mathrm{~Hz}$ ) of the $\gamma$-peaks revealed in both pure cPU and 80/20 sample. In the same temperature range the storage modulus E'(T) (figure 2c) shows the corresponding inflexions, whose magnitude increases with decreasing cPU content. Above $200 \mathrm{~K}, \mathrm{E}$ ”(T) shows the large $\alpha_{\mathrm{a}}$-relaxation peak paralleled by 
corresponding drops in $\mathrm{E}^{\prime}(\mathrm{T})$ (figure 2c), which is associated to the primary relaxation due to the cooperative segmental motions of amorphous chains at the glass transition. All the relaxation peaks shift to higher temperatures as the mechanical driving frequency is increased (see the behaviours reported in figure $2 \mathrm{~d}$ as typical).

The mechanical spectrum of pure S-b-AK exhibits the $\beta$-relaxation at about $186 \mathrm{~K}$ (at $3 \mathrm{~Hz}$ ) and the $\alpha_{\mathrm{a}}$-relaxation at about $360 \mathrm{~K}$ (at $3 \mathrm{~Hz}$ ) [4]. The addition of relatively small amounts of cPU to S-bAK (cPU/S-b-AK=5/95 and 10/90) leads to a significant suppression of both the $\beta$ - and $\alpha_{a^{-}}$ relaxations, whose strengths deviate markedly from a linear concentration behaviour showing a faster decrease with decreasing S-b-AK content, figure $2 b$. The same considerations also result from the analysis of E'(T), the drop associated to the $\alpha_{a}$-relaxation in pure $S$-b-AK being more than twice as large as the one observed in the 10/90 sample, figure 2c. A further relaxation peak is revealed at about $248 \mathrm{~K}$ (at $3 \mathrm{~Hz}$ ) in both the samples having a ratio equal to 5/95 and 10/90. This peak, not observed in pure S-b-AK, shows an increasing strength with increasing cPU content and a $\mathrm{T}_{\text {peak }}$ very close to those of the $\alpha_{\mathrm{a}}$-relaxation peaks in pure cPU and in $t$-IPNs with high concentrations of cPU (figure 2a). As explained in the following, this transition should be associated to an $\alpha_{\mathrm{a}^{-}}$ relaxation process within a cPU/S-b-AK mixed amorphous phase.

\section{§ 4. DISCUSSION}

Prominent thermal features of $t$-IPNs, having the compositions cPU/S-b-AK=90/10 and 80/20, are (i) the increase of $\mathrm{T}_{\mathrm{g}}$ and of the corresponding jumps and (ii) the decrease of $\mathrm{T}_{\mathrm{m}}$ and of the heat of melting with decreasing cPU content. In particular the decrease of the heat of melting $\Delta H_{m}{ }^{*}$, from $74 \mathrm{Jg}^{-1}$ in pure cPU [4], through $50 \mathrm{Jg}^{-1}$ in 90/10, to $37 \mathrm{Jg}^{-1}$ in $80 / 20$ [4], is larger than that expected from a simple dilution effect. The slight depression of $T_{m}$ implies a reduction of the mean size of BAG microcrystals in agreement with the modified Thomson equation [8] (Bershstein and Egorov 1994), $\mathrm{T}_{\mathrm{m}}=\mathrm{T}_{\mathrm{m}}^{0}(1-b /<\mathrm{D}>)$, where $\mathrm{T}_{\mathrm{m}}^{0}$ is the melting point of an ideal infinitely long crystal, $b$ a constant and D the mean size of a microcrystal. From the above results it follows a hindrance to the crystallization of cPU in $t$-IPNs, probably due to a small but significant miscibility between BAG and S-b-AK due to intermolecular hydrogen bonds between the functional groups of the two components. This weak affinity between the two components is assumed to promote the formation of a mixed amorphous phase, characterized by a higher $\mathrm{T}_{\mathrm{g}}$ than that of pure $\mathrm{cPU}$ and coexisting with microphases of pure crystalline BAG and of amorphous S-b-AK. The existence of the mixed phase is also supported by the mechanical relaxation peaks observed around $250 \mathrm{~K}$ (figure $2 \mathrm{~b}$ ) in $t$-IPNs with high concentrations of S-b-AK (cPU/S-b-AK=5/95 and 10/90) which exhibit an increasing strength with growing cPU content. These observations lead to conclude that these latter $t$-IPNs, 
whose thermograms do not exhibit any melting endotherms, can be regarded as wholly amorphous systems having a morphology based on the coexistence of microphases of essentially pure S-b-AK and of mixed cPU/S-b-AK microphases. A further consideration concerns the absence of crystalline BAG in the $t$-IPNs with high concentrations of S-b-AK which, as pointed out in Section 2, were annealed at temperatures close to the melting temperature of BAG. This finding is apparently in contrast with the results of a X-ray scattering study of as-cast $t$-IPNs based on cPU and S/AA random copolymer (acid form) [9], which showed the existence of BAG crystals in the whole range of compositions from pure $\mathrm{cPU}$ to pure S/AA. Besides the structural differences of one of the component ( $\mathrm{S}-\mathrm{b}-\mathrm{AK}$ is a block copolymer), this discrepancy is probably due to the annealing procedure imposed on the present samples which is expected to favour the formation of the mixed amorphous phase preventing BAG crystallization.

Further support for the hindrance to the tendency of BAG to crystallise in $t$-IPNs and for the existence of the mixed amorphous phase is given by the mechanical results. The following considerations are offered:

\section{(i) $\quad \alpha_{\mathrm{a}}$-relaxations}

the strength of the $\alpha_{\mathrm{a}}$-relaxation, observed at about $250 \mathrm{~K}$ in pure cPU and in $t$-IPNs with a weight ratio of 90/10 and 80/20 (figures $2 \mathrm{a}$ and $2 \mathrm{c}$ ), increases with decreasing cPU content as an evidence of a growing non-crystallinity degree. More interestingly, the relaxation peak observed at about the same temperature in $t$-IPNs with weight ratios of $5 / 95$ and 10/90 exhibits a increasing strength with increasing cPU content (figures $2 \mathrm{~b}$ and $2 \mathrm{c}$ ) which is paralleled by a noticeable suppression of the $\alpha_{\mathrm{a}}$-relaxation ascribed to S-b-AK component. It is believed that this peak arises from the cooperative relaxation motion of the amorphous chains within cPU/S-b-AK mixed microphases, whose formation is favoured by thermal annealing of $t$-IPNs at temperatures close to the BAG melting temperature.

\section{(ii) $\gamma$-and $\beta$-relaxations}

the magnitude of the $\gamma$-relaxation peak, which is located at about the same temperature in pure cPU and in $t$-IPNs with weight ratios of $90 / 10$ and $80 / 20$, increases with decreasing cPU content (see figure 2a). In close agreement with the result previously obtained [4], an average activation energy $\mathrm{E}_{\gamma}=0.43 \pm 0.04 \mathrm{eV}$ is obtained for 90/10 $t$-IPN confirming the assignment of this process to crankshaft motions of $\left(\mathrm{CH}_{2}\right)_{\mathrm{n}}$ segments within the amorphous chains $[9,10]$. It is believed that, in $t$-IPNs, this process is due to the contributions of $\gamma$ relaxation within cPU amorphous chains of the mixed phase, whose fraction is enhanced on blending as also observed by the calorimetric results. In all the samples the $\gamma$-relaxation is 
unexplainable in terms of a single relaxation time and has been analysed by the symmetric double-well potential (SDWP) model. It schematizes the locally mobile relaxing particles in terms of symmetric double-well potentials having a broad distribution of the barrier height $E$, which accounts for random variations in the local environments of particles due to the topological disorder. A quantitative analysis was carried out by using a procedure elsewhere detailed $[11,12]$ :

$$
Q^{-1}=\frac{A}{T} \int \exp \left(-\frac{\left(E-E_{m}\right)^{2}}{2 E_{o}^{2}}\right) \times \frac{\omega \tau(E)}{1+\omega^{2} \tau^{2}(E)} d E
$$

where

$$
A=\frac{N B^{2}}{\sqrt{32 \pi} \rho \mathrm{v}^{2} k_{B} E_{o}}
$$

The relaxation time $\tau$ is given by the usual Arrhenius expression, $\tau=\tau_{0} e^{E / k_{B} T} . E_{m}$ and $E_{0}$ represent the most probable activation energy and the width of the distribution, $N$ is the number of relaxing molecular groups, $B$ is an average deformation potential and the other symbols have the usual meanings. Numerical evaluation of the experimental curves by equation (1) gave the following values for the relaxation parameters: $E_{m}=0.34 \mathrm{eV}$, $\mathrm{E}_{0}=0.031 \mathrm{eV}, \mathrm{NB}^{2}=3.97 * 10^{-13} \mathrm{~J}^{2} \mathrm{~m}^{-3}$ and $\tau_{0}^{-1}=1.11 * 10^{13} \mathrm{~s}^{-1}$ for pure $\mathrm{cPU} ; \mathrm{E}_{\mathrm{m}}=0.35 \mathrm{eV}$, $\mathrm{E}_{0}=0.035 \mathrm{eV}, \mathrm{NB}^{2}=7.37 * 10^{-13} \mathrm{~J}^{2} \mathrm{~m}^{-3}$ and $\tau_{0}^{-1}=1.49 * 10^{13} \mathrm{~s}^{-1}$ for $80 / 20 t$-IPN. The theoretical fits are shown by a solid line in the inset of figure 2a. An interesting feature of the results is that the product $N B^{2}$ involving the density of relaxing particles and the deformation potential increases with decreasing cPU concentration. Since no significant change for the deformation potential is expected by going from neat $\mathrm{cPu}$ to $t$-IPNs with weight ratios of 90/10 and 80/20, the quantity in $N B^{2}$, which increases with increasing Sb-AK content, must be the number of relaxing particles. This result represents a further confirmation that the fraction of cPU amorphous chains of the mixed phase is enhanced on blending.

The $\beta$-relaxation, observed at about $186 \mathrm{~K}$ (at $3 \mathrm{~Hz}$ ) in pure S-b-AK [4], is severely suppressed in $t$-IPNs with weight ratios of 5/95 and 10/90 preventing any kind of quantitative analysis in these polymers.

The totality of observations concerning the thermal characteristics and the relaxation dynamics of $t$ IPNs leads to conclude that these systems are characterized by a heterogeneous morphology, based on microphases of pure cPU (BAG crystals), pure amorphous S-b-AK and a cPU/S-b-AK amorphous complex. The phase micro-segregation between cPU and S-b-AK takes place in all 
cases, although a mixed amorphous microphase resulting from the participation of intermolecular hydrogen bonds between the functional groups of the two components and having distinct physical characteristics is formed.

\section{§ 5. CONCLUSIONS}

To gain an insight into the phase behaviour of $t$-IPNs based on semi-crystalline cPU and S-b-AK block-copolymer, a comparative experimental study of differential scanning calorimetry and dynamic mechanical spectroscopy has been made here in samples having different cPU/S-b-AK weight ratios $(90 / 10,10 / 90$ and 5/95). The purpose of making specific heat and mechanical measurements on these systems was to investigate more accurately the weak affinity between the two components, previously revealed in a sample (80/20) belonging to this class of interpenetrating polymers. The heat of melting of the crystalline phase of cPU component shows a faster suppression with decreasing $\mathrm{cPU}$ content than that expected from a simple dilution effect. This finding has been interpreted as a hindrance to crystallization of cPU in $t$-IPNs, due to a small degree of miscibility between BAG and S-b-AK arising from intermolecular hydrogen bonds between the functional groups of the two components. The observation of distinct calorimetric and mechanical transitions have been associated to the heterogeneous morphology of the thermoplastic networks, where microphases of crystalline cPU (BAG crystals) and amorphous S-b-AK coexist with those of a cPU/S-b-AK mixed amorphous complex. The thermodynamic compatibility of the components, even if limited, promotes the formation of the mixed amorphous phase characterized by a higher $\mathrm{T}_{g}$ than that of the amorphous phase of pure cPU. A further indication for the hindrance to crystallizability of BAG on blending is offered by the quantitative analysis of the $\gamma$-relaxation in terms of a symmetric double-well potential model: the amorphous fraction of polyurethane increases with decreasing cPU content. 


\section{REFERENCES}

[1] L.H. Sperling, Interpenetrating polymer networks and related materials, (Plenum Press, New York, 1981).

[2] L.H. Sperling, Interpenetrating polymer networks, edited by D. Klempner, L. H. Sperling and L.

A. Utracki (ACS 239, American Chemical Society, Washington DC, 1984).

[3] J. V. Van Bogart, P. E. Gibson, S. L. Cooper, J. Polym. Sci.: Polym. Phys. Ed. 2165 (1994).

[4] A. Bartolotta, G. Carini, G. D'Angelo, G. Di Marco, F. Farsaci, O. P. Grigoryeva, L. Sergeeva, O. Slisenko, O. Starostenko, G. Tripodo, Phil. Mag. 841591 (2004)

[5] L. M. Sergeeva, O. P. Grigoryeva, O. N. Zimich, E. G. Privalko, V. I. Shtompel, V. P. Privalko, P. Pissis, A. Kyritsis, J. Adhesion 64161 (1997).

[6] S. A. M. Ali and D. J. Hourston, in Advances in Interpenetrating Polymer Networks, edited by

D. Klempner and K. C. Frisch (Technomic Publishing Co, Lancaster, PA, 1994) Vol. IV, p.17.

[7] D. L. Siegfried, D. A. Thomas, and L. H. Sperling, J. Appl. Polym. Sci. 26141 (1981).

[8] V. A. Bershstein and V. M. Egorov, Differential Scanning Calorimetry of Polymers, (Ellis Horwood, London, England, 1994).

[9] A. Kyritsis, P. Pissis, O. P. Grigoryeva, L. M. Sergeeva, A. A. Brouko, O. N. Zimich, E. G. Privalko, V. I. Shtompel, V. P. Privalko, J. Applied Polymer Science 73 (1999) 385.

[10] P. Hedvig, Dielectric Spectroscopy of Polymers, Hilger, Bristol, England, 1977.

[11] A. Bartolotta, G. Di Marco, M. Lanza, G. Carini, J. Polym. Sci. B: Polym. Phys. 33, 93 (1995).

[12] G. Di Marco, A. Bartolotta, G. Carini, J. App. Phys. 71, 5834 (1992). 


\section{FIGURE CAPTIONS}

Figure 1. DSC traces through the glass transition region for the neat cPU (dashed line) and S-b-AK (solid line) and for the $t$-IPNs having the following cPU/S- $b$-AK compositions: $90 / 10$, $(\diamond) ; 80 / 20,(\nabla) ; 10 / 90,(\Delta) ; 5 / 95,(\mathrm{O})$. The curves have been duly shifted for easier comparison. The continuous lines are only guides for eyes.

Fig. 2. Comparison of the dynamical mechanical spectra of $t$-IPNs at a frequency of $3 \mathrm{~Hz}$.

(a) Temperature dependence of the loss modulus E" in: pure cPU, dashed line; cPU/S-b$\mathrm{AK}=90 / 10,(\mathrm{O})$; $\mathrm{cPU} / \mathrm{S}-\mathrm{b}-\mathrm{AK}=80 / 20,(\Delta)$. The inset reports the comparison between the experimental data for the internal friction at $30 \mathrm{~Hz}$ across the $\gamma$-relaxation peak and the theoretical fits by Eq. (1) in neat $\operatorname{cPU}(\bullet)$ and in $t$-IPN $(\Delta)$ with a weight ratio of 80/20.

(b) Temperature dependence of the loss modulus E" in: pure S-b-AK, solid line; cPU/S-b$\mathrm{AK}=5 / 95,(+) ; \mathrm{cPU} / \mathrm{S}-\mathrm{b}-\mathrm{AK}=10 / 90,(\nabla)$.

(c) Temperature dependence of the storage modulus E' in: pure cPU (dashed line) and S-bAK (solid line); cPU/S-b-AK=90/10, (O); cPU/S-b-AK=80/20, ( $\Delta$ ); cPU/S-b-AK=10/90, $(\nabla)$.

(d) The effect of the driving frequency on the temperature dependence of E' in cPU/S-b$\mathrm{AK}=10 / 90: 0.3 \mathrm{~Hz},(\mathrm{O}) ; 3 \mathrm{~Hz},(+) ; 30 \mathrm{~Hz},(\Delta)$. 
FIG. 1

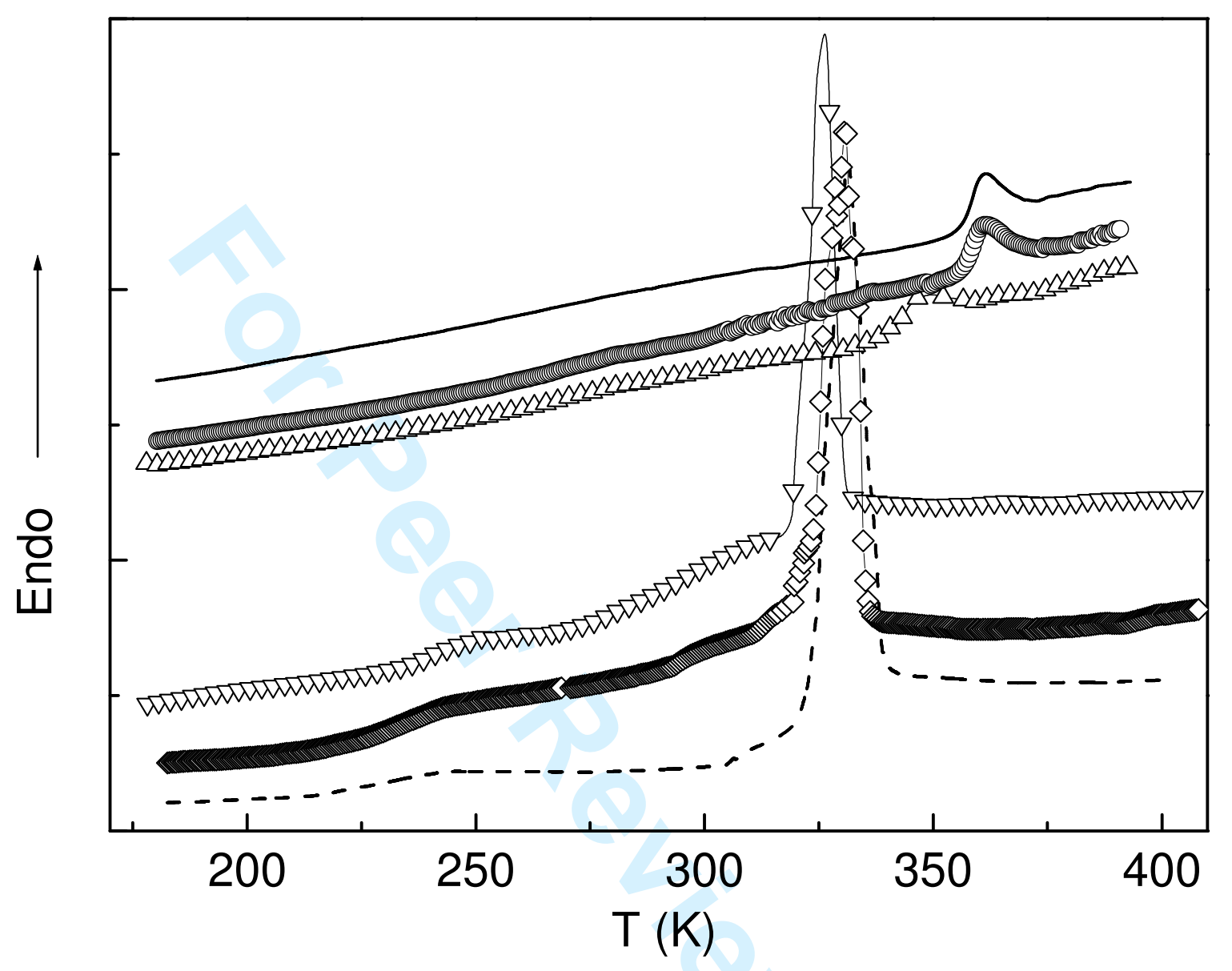


Fig. 2

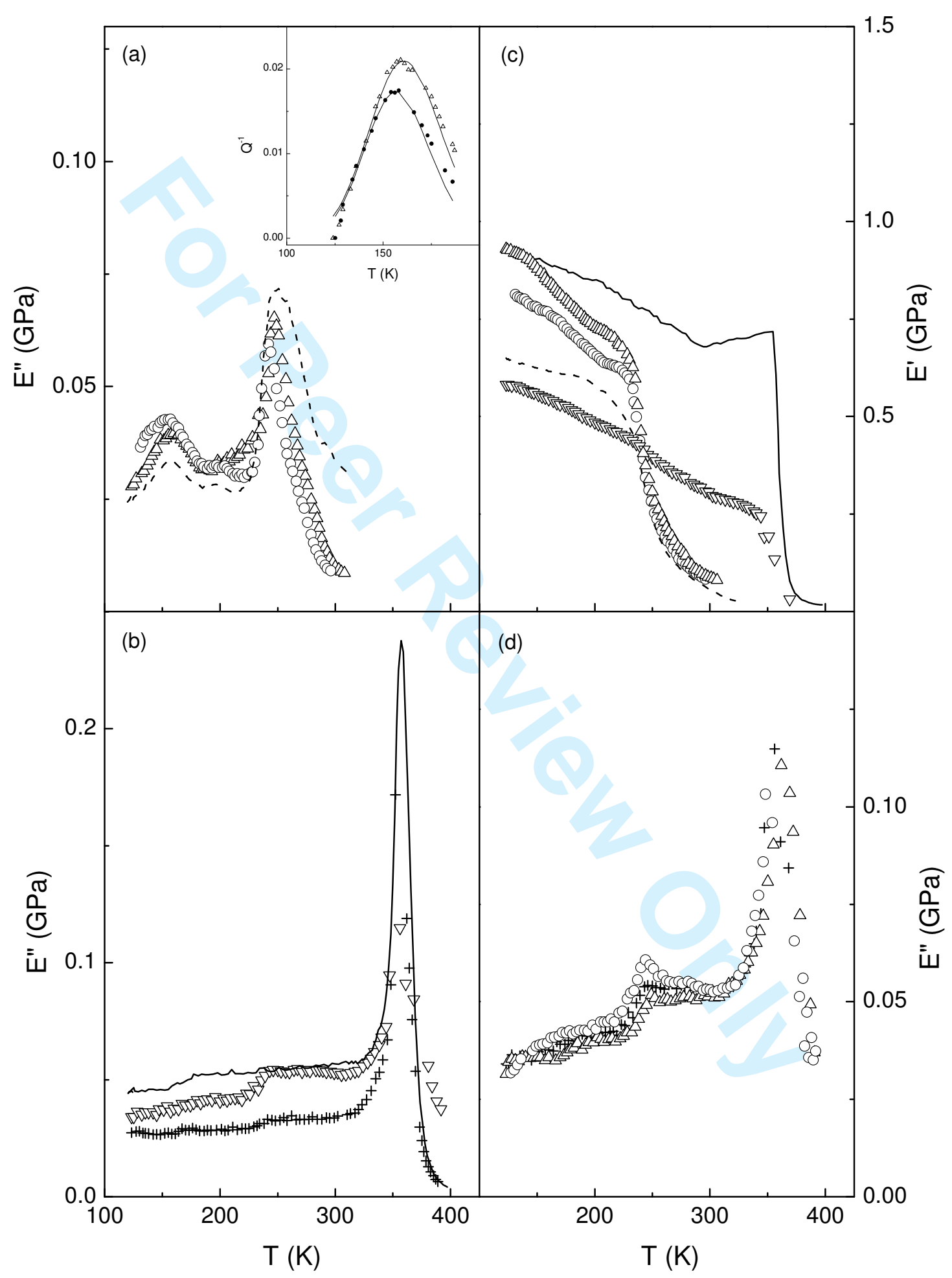




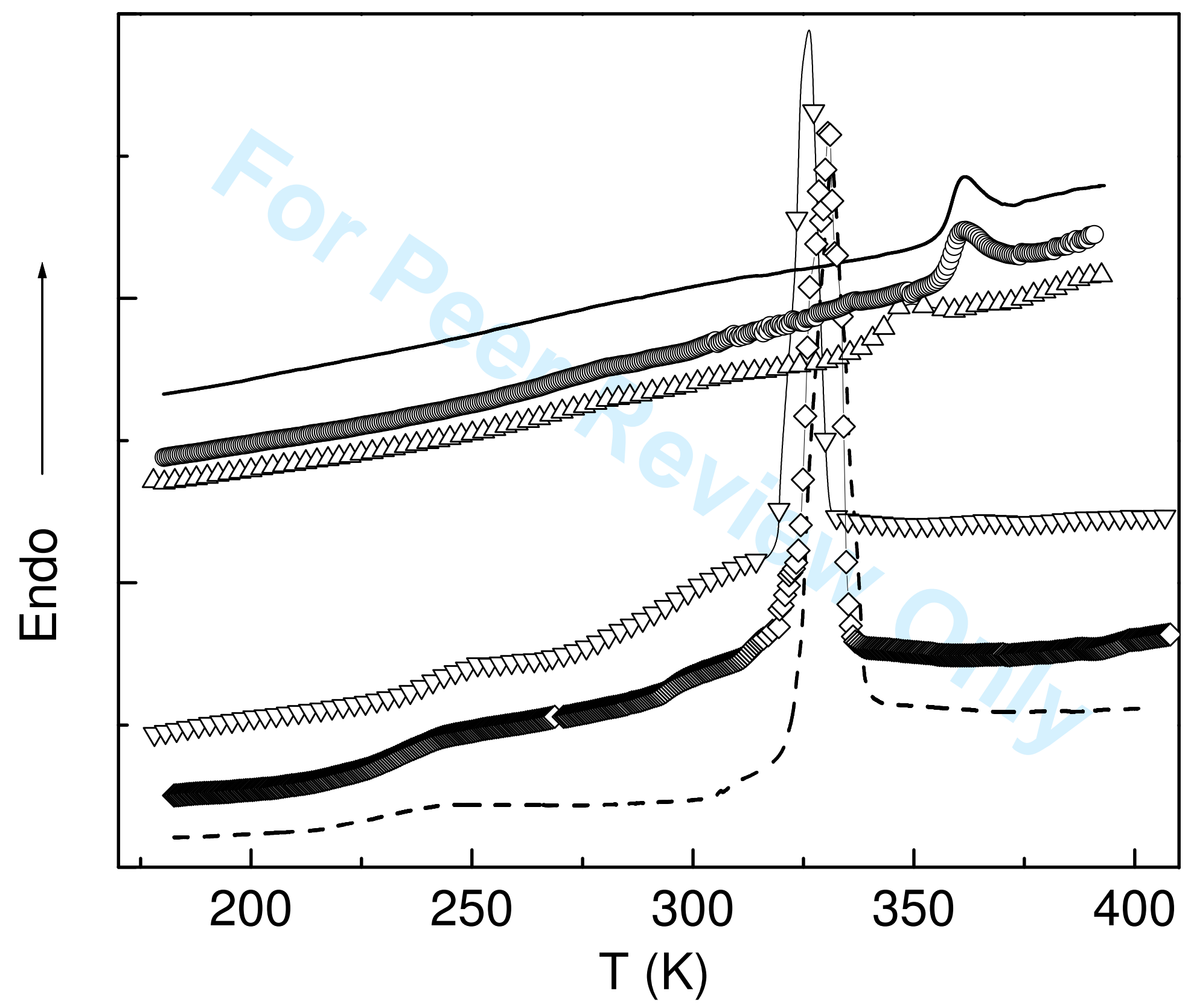

http://mc.manuscriptcentral.com/pm-pml 
Fig. 2

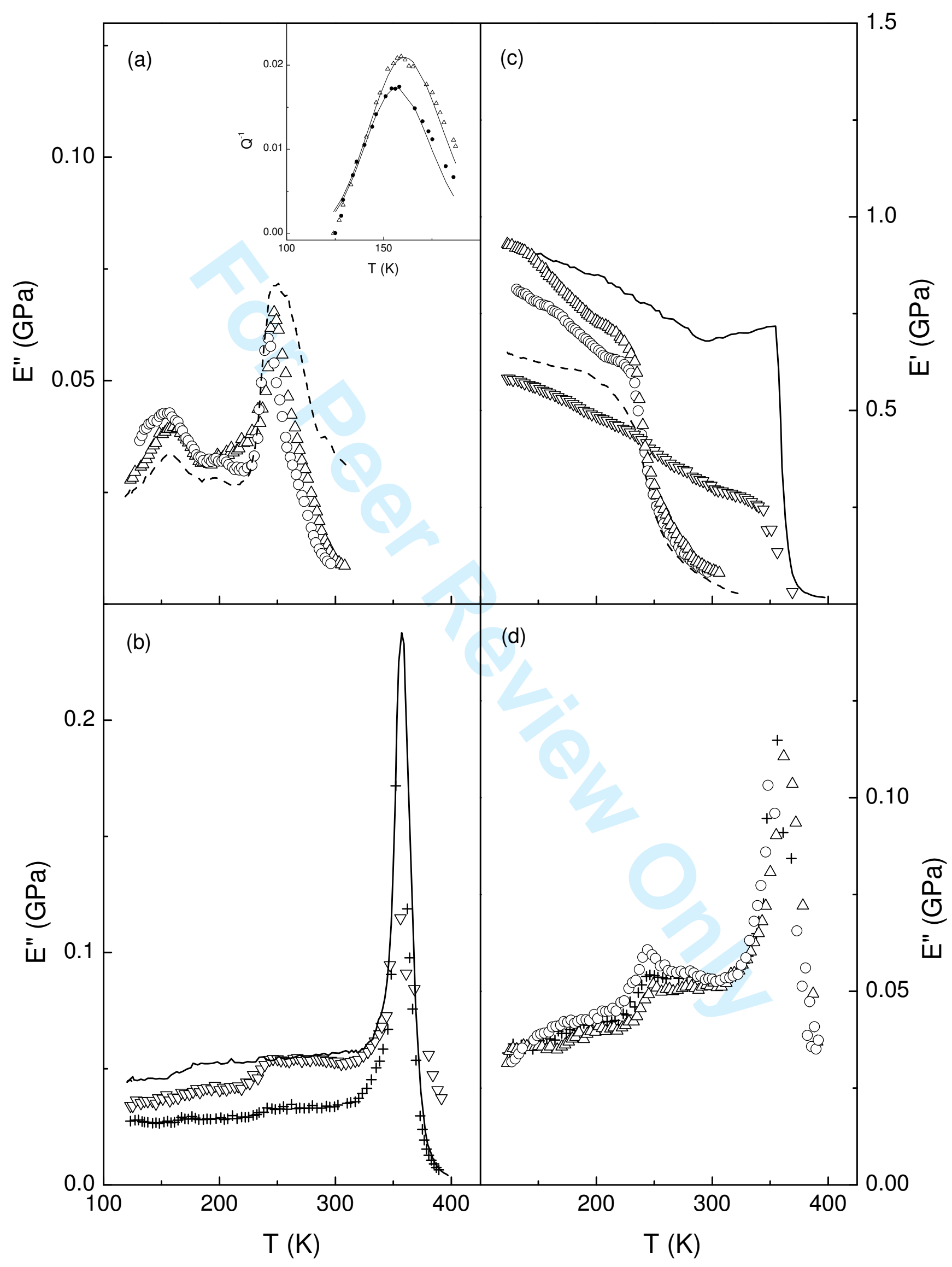

